\title{
Intelligent Agent and Virtual Game to support education in e-health
}

\author{
Enrica Pesare, Teresa Roselli, Veronica Rossano \\ Department of Computer Science \\ University of Bari \\ Via Orabona, 4 \\ \{enrica.pesare, teresa.roselli, veronica.rossano\}@uniba.it
}

\begin{abstract}
The education in e-health play an important role in particular in context of chronic diseases. The empowerment process aims at enhancing the patient knowledge and skills in order to allow them to be aware of their health status. The paper presents a serious game that is addressed to young children with type I diabetes and uses the coaching strategy. The coach has been designed and developed as an Intelligent Agent using a knowledge base about the diabetes intervenes to suggest the best action to do or to correct wrong behaviours. A first pilot test was conducted to measure the learning effectiveness and usability of the game. The results were promising.
\end{abstract}

Virtual game; Intelligent game; Serious game; Coaching strategy.

\section{INTRODUCTION}

The success and effectiveness technology use to support education and training are universally recognized. In the recent years, the use of ICT is spreading as tools to support also therapeutic education. Even the European Community is sponsoring and encouraging this trend, as can be noticed in the ICT calls of Horizon 2020 work programme. Many ICT solutions, in fact, are addressed to the patient empowerment [7, $8,13,15,22,24]$. The concept of empowerment can have different meanings: strengthening, self enhancement, power increase, increased personal responsibility and knowledge; the patient should constantly monitor her/his status and learn to recognize potentially dangerous situations for her/his health.

In this case, the process of empowerment is fundamental: it begins from the first hospitalization when the diagnosis is confirmed and lasts for life. The use of new technologies, in these cases, can also act on the psychological state of the patient and make training more effective. This is especially true when patients are very young, as in the case of type I diabetes mellitus, that occurs in children and it is caused by a congenital lack of insulin production. Because of patients' young age, it is essential that parents learn quickly how to keep the blood sugar balance to ensure them a good health, and for the patients themselves to learn the glycemia self-management, to allow them to enjoy the same activities of their peers in safety. Moreover, the empowerment process should support the acquisition of knowledge and skills that allow the young people to play an active role in the management of their disease.
With these premises, the authors, in collaboration with a team of practitioners of the "Metabolic Diseases and Medical Genetics Unit" of "Giovanni XXIII" Pediatric Hospital in Bari and with the APGD (Association of Apulian Young Children with Diabetes) have developed different technological solutions to support learning and training processes [7, 8, 22, 24]. The paper presents a serious game addressed to young people. The coaching strategy has been used in order to supply some suggestion to the player during the game. The coach has been designed and developed as a simple reflex agent: based on condition-action rules in the knowledge base, it suggests the best action to do or to correct wrong behaviours.Teaching strategies

In the specific context of patient empowerment the motivation and the user engagement are two key factors to assure a high level of learning effectiveness [19]. In addition, if the final users are young people, as in case of type I diabetes, it is important to use teaching strategies able to maximize their outcomes without overwhelming them.

\section{A. Coaching}

Coaching represents one of the teaching strategies most popular in learning/teaching settings. It was defined by Goldstein \& Carr [11], who used the athletic paradigm to illustrate how the computer could act as a coach in educational settings. They used this concept, borrowed from sports and athletics, in order to transfer serious intellectual skills. The coaching strategy is less invasive for the learners than the Socratic method, where in order to stimulate critical thinking the teacher uses a form of inquiry and debate based on asking and answering questions. In coaching, the observation of the teacher (coach) is non-invasive; for example, in soccer the coach stays outside the football field, where he observes and suggests actions that can contribute to improve the player's performance. Since the coaching is a non-invasive strategy, it represents one of the best strategies for the patient's empowerment. In this case, in fact, the intervention of a trainer is essential to help the trainee in the self-empowerment process because patients should become aware of their abilities and use them to improve their health status.

One-to-one tutoring methods such as coaching are very effective. Empirical evidences showed that students, who are 
supported by a skilled tutor in a one-to-one setting, performed better than the students who learned in a classroom setting with the same material [2]. Since a one-to-one tutor is expensive, the use of intelligent agents could combine personal characteristics of the subject with the need of a training process organization to ensure high learning performances.

\section{B. Game based learning and Serious Game}

The origins of game-based learning theory can be found in the Vygotskij's works, then, thanks to the spreading of digital games, it has gained high attention. In particular, Prensky [25] states that the digital game-based learning is a way to create new opportunities and effective learning tools for students who grew up with computers and video-game since chilhood. As a matter of fact, the game-based learning promotes at the same time fun and engagement and aims at making the achievement of educational goals easier, more student-centered, and therefore more effective.

But those opportunities are not only reserved to the digital natives; in fact, as stated by Papastergiou [23], games are poweful learning environments to promote both knowledge and skills acquisition, thanks to their capability to support several pedagogical aspects [20, 21, 23].

For these reasons, in the latest years the Serious Games (SGs) are becoming one of the widely tools used in learning contexts. De Freitas 2006 [10] defines SGs as “....applications using the characteristics of video and computer games to create engaging and immersive learning experiences for delivering specified learning goals, outcomes and experiences." It is clear that, this kind of immersive and experiential tools for learning will be usefull not only in traditional learning contexts, where the knowledge has to be acquired, but also in training contexts where the previous knowledge has to be applied. Furthermore, SGs make step forward in comparison with serious playing [27]: by combining the realism of simulation with the clearness of the game instructions and goals. They provide a controlled environment to practice and experience serveral options: the game environment prevents users from anxiety and fear of consequences. The effectiveness of SGs has been proven in serveral domains, such as science $[3,4,14,18]$ and humanities $[5,16,26,28]$, but also in the e-health field where the need of joining knowledge and practical skills is more pushing, as reported in [1, 6, 7, 8, 9, 13, 15, 22, 24].

These are the premises of our research work where the coaching strategy has been integrated in a serious game to create a vitual game aimed at supporting young patients in the self-empowerment process in the contest of type 1 diabetes. In particular, the patients are asked to acquire the knowledge and the skills to help them to self-manage their clinical conditions and especially to prevent serious hypoglycaemic events and reducing psychological burdens.

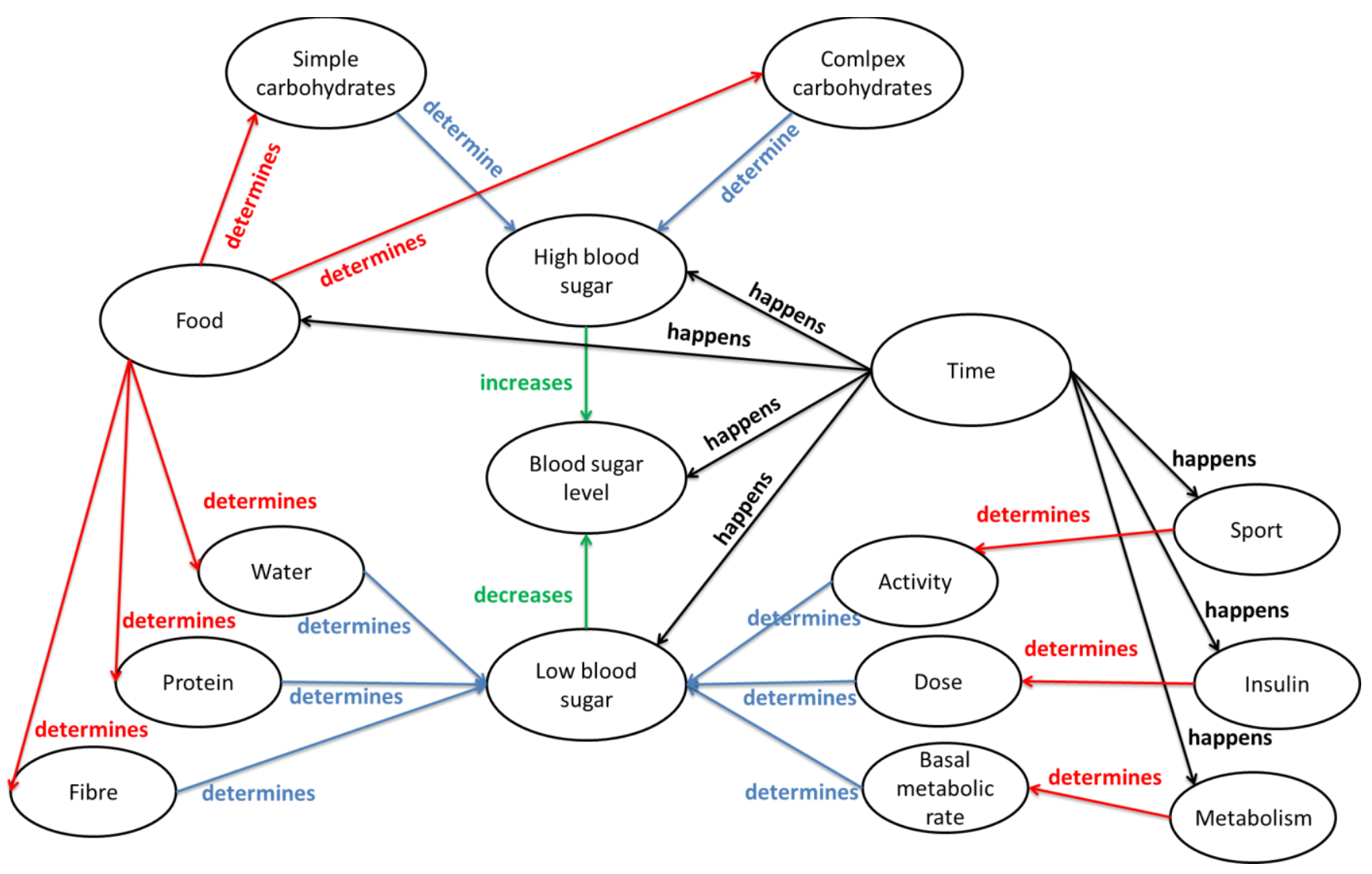

Figure 1. Knowledge model representation 


\section{VIRTUAL COACH}

Virtual Coach is a virtual game that combines pedagogical strategies, such as coaching and game-based learning [25], with the techonological issues of serious game [27] and intelligent agent in order to educate the young users to adopt an adequate lifestyle and to control the glycemic balance.

The system is a game simulation that allows the user to take care of a virtual character, supported by the presence of a doctor, as virtual coach. The coach intervenes to give suggestions and to correct wrong attitudes. The use of the game is a specific communication strategy to make the training process more pleasant for the young and to increase user engagement and motivation, essential elements to make the learning effective [23].

\section{A. The game mission}

The mission of the game is to help a virtual patient, named Mario, to make the right choices during everyday life. The ultimate aim is to train the patient to handle the normal activities, such as breakfast, homework, play, and so on.

\section{B. The game organization}

In the game the user faces with two types of days: a school day and a non-working day, such as Sunday or public holiday. During the day different activities are scheduled, according to the type of the day, and different scenarios have been designed. Each scenario represents the most important moments of the patient's life. For diabetic children, for example, it is important to understand what behaviour to adopt during meals and physical activities in order to control the blood sugar levels.

\section{Learning objectives}

In order to reach the specific learning goal, different basic issues have been defined with the practitioners: what kind and how many physical activities could be done; what foods and how many of them could be eaten; and when and how many insulin should be injected.

\section{Knowledge topics}

As said before, in the virtual game there is a coach, represented by a doctor avatar, which intervenes to suggest the right behaviour or to correct wrong user's actions. To allow the coaching activities, a model of the knowledge about the type I diabetes has been defined (Fig. 1). In particular, the knowledge base has to be aware of the blood glucose metabolism, in other words it is necessary that the virtual game knows why and when the blood glucose increases and why and when it decreases. For example, the blood glucose increases faster when you eat fruits rather than when you eat a slice of bread. In this context, the representation of the Time in the knowledge base has a key role.

\section{THE GAME ARCHITECTURE}

The game has been designed as a client-server web application (Fig. 2). The different components are:

- $\quad$ the knowledge base (server side) developed using the Prolog language;

- $\quad$ the inference engine (server side) composed of two different modules, one to calculate the blood sugar level and one for the fluent calculus;

- $\quad$ the user interface (client side) to allow the user to interact with the system.

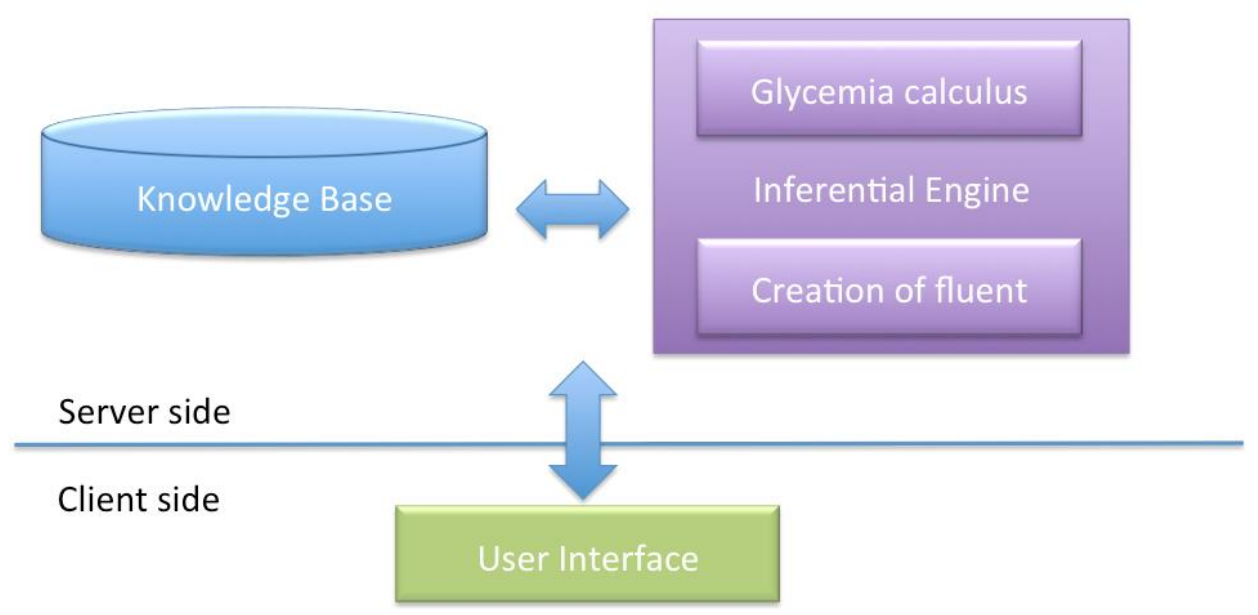

Figure 2. Game architecture 


\section{A. The knowledge base}

As said before in the blood sugar metabolism it is essential understand how the level of glucose can vary during the day. Different kind of foods and macronutirients (simple or complex charboydrates, proteins, fiber, water) as well as different kind of activities (basal metabolism, sport activities or insulin injection) have different impact on the blood sugar levels according to the time (Fig.1).

For this reason the fluent calculus has been used to formalize the increasing and decreasing of glycaemia:

- fapporto_glicemico (Ti, Tf, Varmin): represents the increasing of glycaemia in a specific slot of time;

- fdiminuzione_glicemica (Ti, Tf, Varmin): represents the decresing of the glycaemiain a specific slot of time.

$\mathrm{Ti}$ is the start time of the fluent, that is the time when an event occurs,; $T f$ is the end time of the fluent, calculated according to the knowledge base rules; Varmin is the variation of the glycaemia per minute, that depends on the kind of event.

For example, the event that improves the glycaemia is the food. Let us to suppose that the player gives to Mario some cookies at 4.00 PM, the fluent fapporto_glicemico is started. Both Tf and Varmin depend on the quantity of carbohydrates and the type, in the specific case the glycaemia will increase of $0,5 \mathrm{mg} / \mathrm{dl}$ per gr and the fluent will last 120 minutes, since the cookies contain complex carbohydrates. This allows the blood sugar level in Mario to be calculated. In the same way, events, such as insulin, sport, metabolism, will be responsible for the reduction of glycemia. In those cases the fdiminuzione_glicemica fluent will be activated.

All the events are the results of the possible player interaction within the virtual game.

\section{B. The inference engine}

The inference engine has two main components:

- Creation of the fluents module

- Glycaemia calculus module

The first module is addressed to the definition of the different type of events that can occur in the virtual game. It defines which type of fluent should be activated. Moreover, the module has to define the parameters of the fluent based on of the different type of events. When the fluent is created, an assertion is written in the knowledge base in order to calculate the glycemia.

The second module allows the glycaemia to be calculated in a specific slot of time and allows the transition to the following scenarios with a specific blood sugar value. In order to calculate it, the fluent glicemia (Glicemia, Tglic) was defined. The parameters represent the value of glycaemia (Glicemia) at a specific time (Tglic) in the game. When the player starts the game a random value of glycaemia is defined by the system.

In order to well understand how the knowledge base is used, let us suppose that when the day starts at 7.00 AM the random value of Mario glycaemia is 100 , Tglic is 0 , the fluent glicemia $(100,0)$ starts. At 7.00 the scenario in the game is usually the breakfast, the player gives to Mario 50gr of complex carbohydrates (cookies). Since the action of eating cookies means that the blood sugar level increases, the fluent fapporto_glicemico is started. Using a mathematical function that emulates the blood sugar metabolism, both $T f$ and Varmin are calculated, their values, as said before, depend on the quantity and type of food eaten. In this specific case, $T f$ will assume the value of 120 minutes and Varmin is 1.3875. When the player changes the scenario, let us suppose that are the 8.00 $\mathrm{AM}$, since 60 minutes are passed in the game, the new glycaemia value is calculated by the fluent glicemia taking into account that the fapporto_glicemico fluent is active until 9.00 AM.



Figure 3. The introduction to the interaction 


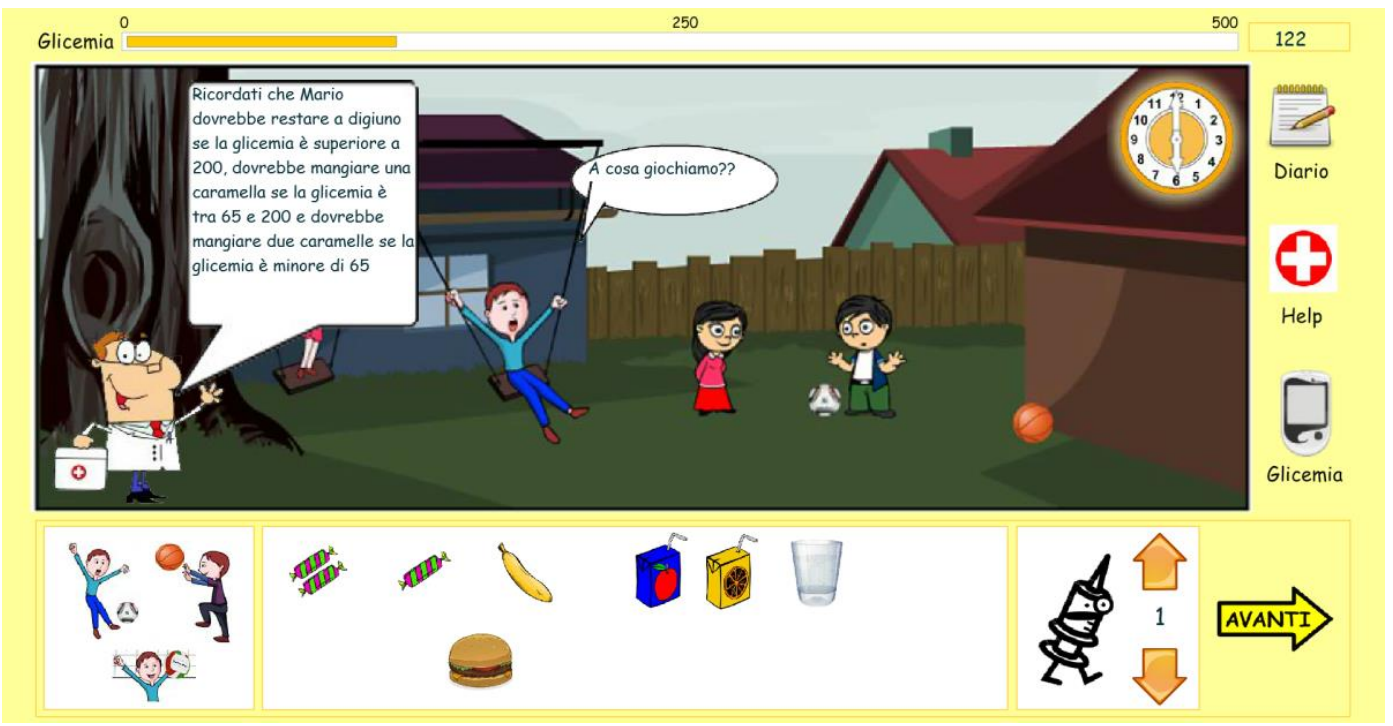

Figure 4. The virtual coach gives some advice before Mario plays with his friends

\section{The user interface}

The virtual game starts with the doctor avatar (the virtual coach) that introduces the game and the characters (Fig. 3).

The doctor avatar is always visible in the left side of the main scenario, where Mario is interacting with other carathers. (Fig. 4). The main elements in the right side of the screen are:

- The clock used to allow the player to monitor the time flow. It is useful to understand how the blood sugar level change during the day.

- The diary where the system writes all the actions performed by the player, such as eating food, playing sport, and measuring blood glucose (Fig 5). The diary is useful to allow the player to think over the relationship between her/his actions and the glycaemia metabolism.
- $\quad$ The help button to ask the coach help. He can provide some usefull tips during the game.

- The glucometer to visualize a sliding bar with the glycaemia values.

The main elements at the bottom of the screen are the available actions. Different options are proposed according to the current scenario (Fig. 3 and Fig. 4). From the left side there are:

- $\quad$ different types of sport to be played;

- $\quad$ the foods that can be offered to Mario;

- $\quad$ the insulin doses to be supplied;

- $\quad$ the button to go ahead in the game.
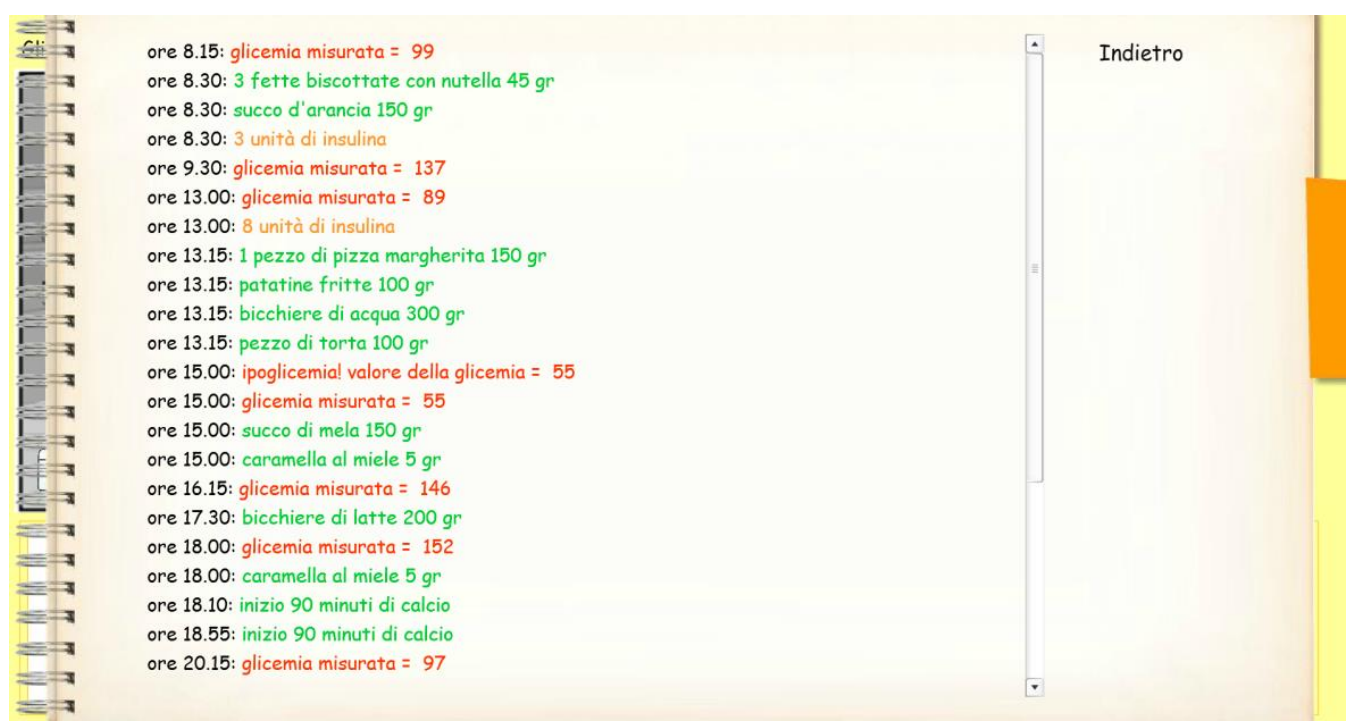

Figure 5. The glycaemia diary 


\section{PILOT STUDY}

In order to measure the learning effectiveness of the virtual game a hypothesis test was conducted. The defined hypothesis where:

- $H_{0}$ (null hypothesis) there is no statistically significant difference between the user knowledge about blood sugar levels management before the use of the virtual game and after it;

- $\quad H_{a}$ (alternative hypothesis) there is a statistically significant difference between pre and post user knowledge about blood sugar levels management.

\section{A. Participants}

The pilot study involved twenty children, aged from 8 to 12, patients of the "Metabolic Diseases and Medical Genetics Unit" of "Giovanni XXIII" Pediatric Hospital in Bari under the supervision of Dr. Elvira Piccinno and Dr. Elda Frezza, medical experts.

\section{B. Pre-experimental design}

The pilot study was conducted using the "one group pre-test post-test study" [12].

The benefit of this design is the use of a pretest to determine baseline scores and a post test in order to measure the outcome of the treatment. In this case, the treatment is the use of the virtual game and the expected outcomes is the improving of the knowledge about type I diabetes and blood sugar levels management. Both pretest and posttest were accurately defined with the practitioners.

\section{Procedure}

The pilot study consisted in two sessions, each one lasted an hour.

During the first session all subjects underwent an individual pre-test to assess their prior knowledge about diabetes, and they were asked to use the virtual game for at least half an hour in order to become familiar with the game.

The second day (second session), they were asked to use the virtual game, and then to answer the post-test in order to evaluate the knowledge gain.

\section{Results}

In order to evaluate the pilot study results the Wilcoxon signed-rank test was used [29]. The Wilcoxon is a nonparametric test used as an alternative to the Student t-test when the population cannot be assumed to have a normal distribution [17]. After the computation of statistical significance, if the pvalue is higher that the predefined level (fixed at 0.05) the $H_{0}$ (null hypothesis) could be accepted, otherwise $H_{a}$ (alternative hypothesis) has to be accepted.
In Table 1 all the results obtained by the subject are reported. The first observation is that in almost all cases, except two users, there was an improvement of knowledge between pretest and posttest.

Moreover, p-value obtained is lower then 0.05, then the alternative hypothesis has to be accepted: there is a significant difference between the pretest and the posttest.

Table 1. Pretest and Posttest results

\begin{tabular}{|c|c|c|c|}
\hline User & Pretest & Posttest & Difference \\
\hline 1 & 7 & 9,50 & 2,5 \\
\hline 2 & 6 & 8,50 & 2,5 \\
\hline 3 & 7,5 & 8,00 & 0,5 \\
\hline 4 & 3,5 & 5,00 & 1,5 \\
\hline 5 & 6 & 8,50 & 2,5 \\
\hline 6 & 6 & 8,00 & 2,0 \\
\hline 7 & 5 & 7,50 & 2,5 \\
\hline 8 & 0 & 2,50 & 2,5 \\
\hline 9 & 6 & 8,00 & 2,0 \\
\hline 10 & 8 & 9,50 & 1,5 \\
\hline 11 & 9 & 9,00 & 0,0 \\
\hline 12 & 9 & 9,50 & 0,5 \\
\hline 13 & 6 & 7,50 & 1,5 \\
\hline 14 & 6,5 & 8,25 & 1,8 \\
\hline 15 & 3,75 & 6,00 & 2,3 \\
\hline 16 & 9,5 & 9,50 & 0,0 \\
\hline 17 & 5 & 7,50 & 2,5 \\
\hline 18 & 7 & 9,00 & 2,0 \\
\hline 19 & 6 & 7,50 & 1,5 \\
\hline 20 & 7,5 & 9,75 & 2,3 \\
\hline Mean & 6,14 & 7,57 & 1,4 \\
\hline
\end{tabular}

In addition, a deeper analysis of the collected data allowed us to find that the virtual game had a great impact on the ability to recognize the different kind of carbohydrate. In fact, the mean knowledge gain was higher on this topic than the knowledge gain on hypoglicemia and hyperglycaemia (Fig. 6). The main reason of this difference is that the virtual game is mainly devoted to acquire competences about type I diabetes, such as to distinguish complex carbohydrates from simple carbohydrates and how much of them could be eaten to balance the blood sugar level. 


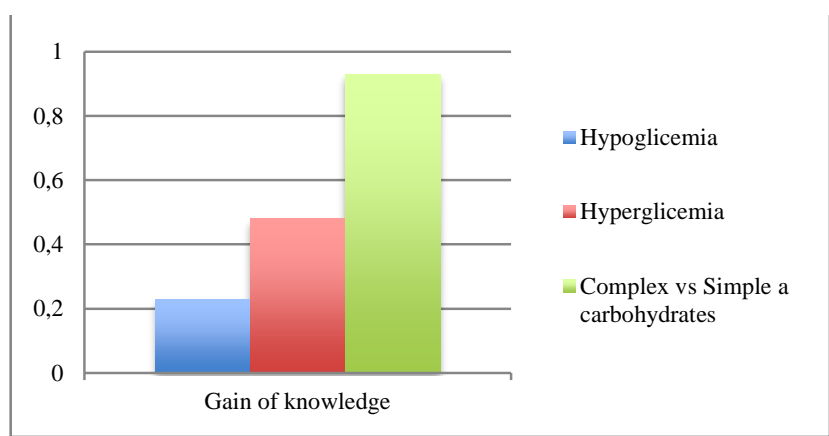

Figure 6. Mean knowledge gain for each topic

\section{E. Usability results}

Usability test or inspection are the more common methods to understand whether users feel comfortable with the software. In educational context, and in particular, when the multimedia is addressed to patient empowerment it is important to know how much the user likes using the system. For this reason after the post-test the users were required to give some feedback on different aspects of the game.

The learnability was judged positive from the users.

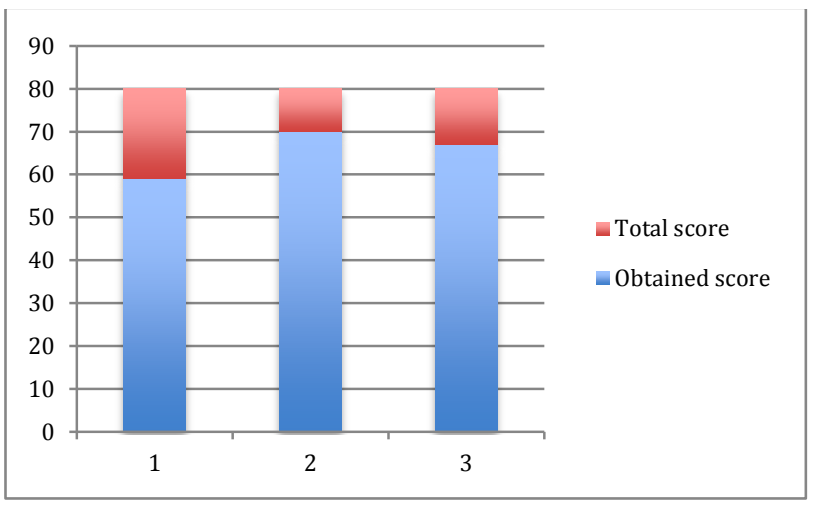

Figure 7. Learnability results

Also the efficiency that measures how fast the user can accomplish a task, was appreciate by the users.

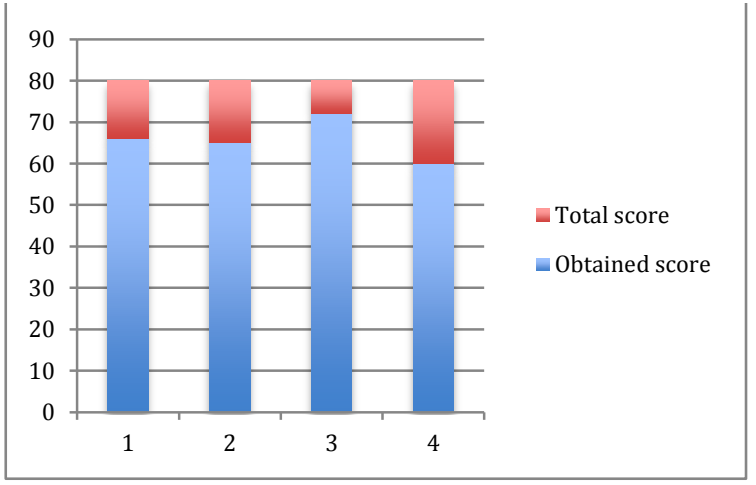

Figure 8. Efficiency results

Finally, the users like using the system, obtained score 66 out 80, and they claim that would suggest the use of the game to their friends. In particular, some of the subjects stated that the virtual game could be more effective for those children who are new to the type I diabetes.

\section{CONCLUSIONS AND FUTURE WORKS}

To guarantee a good quality of life with chronic diseases it is basic to have a proper lifestyle. Thus, it is important that an empowerment process starts from the first hospitalization or when patient become aware of the disease. This is particularly true in type I diabetes where the patients are young children. In order to do everything, like their friends, they need to learn how the glycaemia metabolism works and how they can avoid hypoglycaemia and hyperglycaemia events. For this purpose our research, conducted with a team of practitioners of "Metabolic Diseases and Medical Genetics Unit" of "Giovanni XXIII" Pediatric Hospital in Bari, led us to design and build different solutions aimed to support the educational processes of young patients. The use of new technologies and the game approach is the key to keep the user motivated and engaged in the learning process. The proposed virtual game uses the coaching strategy in order to allow basic concepts and skill about diabetes to be acquired. The coach, who is represented in the game as a doctor avatar, intervenes when wrong actions are taken by the player. To do this a knowledge base and an inference engine were defined in order to simulate the glycaemia metabolism. A first pilot study has demonstrated both the learning effectiveness and the appreciation of young patients and their parents.

In the next future will be necessary to improve the number of the available choices for the player and to conduct an experiment with a larger sample.

\section{ACKNOWLEDGMENT}

We would like to thank Antonio Simmaco and Giuseppe Grosso who developed the virtual game during their Master Thesis in Informatics, the APGD (Association of Apulian Young Children with Diabetes) and all the young children that participate to the study.

\section{REFERENCES}

[1] Berni, F., Corriero, N., Pesare, E., Rossano, V., Roselli., T.: A Knowledge Management Service for e-health. In: ICERI2013 Proceedings, pp. 488-493. ISBN: 978-84-616-3847-5. (2013)

[2] Bloom, B. (1984). The 2 sigma problem: The search for methods of group instruction as effective as one-to-one tutoring. Educational Researcher, 13, 4-16.

[3] Bos, N., \& Shami, N. S. (2006). Adapting a face-to-face role-playing simulation for online play. Educational Technology Research and Development, 54(5), 493-521.

[4] Cagiltay, N. E. (2007). Teaching software engineering by means of computer-game development: Challenges and opportunities. British Journal of Educational Technology, 38(3), 405-415.

[5] 29Chou, C., \& Tsai, M. J. (2007). Gender differences in Taiwan high school students' computer game playing. Computers in Human Behavior, 23(1), 812-824.

[6] Corriero, N., Di Bitonto, P., Roselli, T., Rossano, V., Pesare, E.: Simulations of clinical cases for learning in e-health. In: International Journal of Information and Education Technology, International 
Conference on Information and Education Technology (ICIET) Melbourne, 2-3 January, 2014.

[7] Di Bitonto, P., Roselli, T., Rossano, V., Frezza, E., Piccinno, E. (2012). An educational game to learn type 1 diabetes management. In: The 18th International Conference on Distributed Multimedia Systems. Miami Beach, USA, 9-11 August, 2012, p. 139-143, SKOKIE, ILLINOIS:KSI Press, ISBN: 1-891706-32-2

[8] Di Bitonto, P., Rossano, V., Roselli, T., Piccinno, E., Ortolani, F., Frezza, E., \& Tummolo, A. (2014). Gamification to train young diabetic to manage the insulin metabolism. INTED2014 Proceedings, 3586-3592.

[9] Di Bitonto, P., Di Tria, F., Roselli, T., Rossano, V., Berni, F.: Distance Education and Social Learning in e-Health. International Journal of Information and Education Technology, vol. 4, no. 1, pp. $71-75$ (2014)

[10] De Freitas, S. (2006). Learning in immersive worlds. London: Joint Information Systems Committee.

[11] Goldstein, I. and Carr, B. (1977) The computer as coach: As athletic paradigm for intellectual education. In Proceedings of the 1977 annual conference (ACM '77). ACM, New York, NY, USA, 227-233.

[12] Heffner, C. L., Research Methods, AllPsych Editor available at http://allpsych.com/researchmethods/preexperimentaldesign/\#.VVvFfJN $\underline{\mathrm{X} 9 \mathrm{E} 4}$

[13] Kato, P. M., S. W. Cole, et al. (2008). A Video Game Improves Behavioral outcomes in Adolescents and Young Adults With Cancer: A Randomized Trial. Pediatrics 122(2): 305- 317.

[14] Kiili, K. (2007). Foundation for problem-based gaming. British Journal of Educational Technology, 38(3), 394-404.

[15] Lieberman, Debra A., Interactive video games for health promotion: Effects on knowledge, self-efficacy, social support, and health. In: Street, Richard L., Jr., Gold, William R., Manning, Timothy R. (Eds), Health promotion and interactive technology: Theoretical applications and future directions, (pp. 103-120). Mahwah, NJ, US: Lawrence Erlbaum Associates Publishers, (1997).

[16] López, J. M. C., \& Cáceres, M. J. M. (2010). Virtual games in social science education. Computers \& Education, 55(3), 1336-1345.

[17] Lowry, Richard. Concepts \& Applications of Inferential Statistics http://vassarstats.net/textbook/.

[18] Mayo, M. J. (2009). Video games: a route to large-scale STEM education?.Science, 323 (5910), 79-82.
[19] McCarley, P. (2009). Patient empowerment and motivational interviewing: engaging patients to self-manage their own care. Nephrology nursing journal,36 (4), 409-413.

[20] McFarlane, A., Sparrowhawk, A., \& Heald, Y. (2002). Report on the educational use of games. Teachers evaluating educational multimedia.

[21] Oblinger, D. G. (2004). The next generation of educational engagement. Journal of interactive media in education, 2004(1).

[22] Ortolani, F, M. Vendemiale, A. Tummolo, P. Di Bitonto, V. Rossano, Roselli T, E. Piccinno (2014). Learning by doing approach: use of multimedia applications in type 1 diabetic children. In: ESPE DUBLIN 53rd Annual Meeting. european society for pediatric endocriinology, DUBLIN, 18-20 SEPTEMBER

[23] Papastergiou M., Digital Game-Based Learning in high school Computer Science education: Impact on educational effectiveness and student motivation. In: Computers \& Education, 52 (1), 2009, pp. 1-12.

[24] Piccinno, E., Vendemiale, M., Tummolo, A., Ortolani, F., Frezza, E., Torelli, C., Di Bitonto, P., Rossano, V., Roselli, T. New technologies for promoting hypoglycaemia self- management in type 1 diabetic children. In: 9th Joint Meeting of Paediatric Endocrinology. Milan, 19-22 September, 2013.

[25] Prensky, M. Digital Game-Based Learning. McGraw-Hill, New York, 2001.

[26] 28Ravenscroft, A. (2007). Promoting thinking and conceptual change with digital dialogue games. Journal of Computer Assisted Learning, 23(6), 453-465.

[27] Rieber, L. P. (1996). Seriously considering play: Designing interactive learning environments based on the blending of microworlds, simulations, and games. Educational Technology Research \& Development, 44(2), 43-58.

[28] 27Tüzün, H., Yılmaz-Soylu, M., Karakuş, T., İnal, Y., \& Kızılkaya, G. (2009). The effects of computer games on primary school students' achievement and motivation in geography learning. Computers \& Education, 52(1), 68-77.

[29] Wilcoxon, Frank (Dec 1945). "Individual comparisons by ranking methods" Biometrics Bulletin, Vol. 1, No. 6. (Dec., 1945), pp. 80-83. 